\author{
Christian Wider \\ Thierry Kuntzer \\ Ludwig-Karl Von Segesser \\ Salah Dine Qanadli \\ Julien Bogousslavsky \\ François Vingerhoets
}

\section{Bilateral compressive lumbosacral plexopathy due to internal iliac artery aneurysms}

Received: 16 August 2005

Received in revised form: 19 October 2005

Accepted: 7 November 2005

Published online: 7 February 2006

Sirs: A 75-year-old man was referred to our outpatient clinic for progressive walking difficulties for 1 year, with lightning pain and tingling in both legs. Thirteen years earlier, he had presented with a right parietal spontaneous brain haemorrhage, with mild residual left hemisyndrome.

On examination, a left-predominant bilateral distal leg weakness was found. Ankle reflexes were absent, patellar reflexes were weak. There was partial sensory loss for all modalities under the knee with a left predominance. Stance and gait were on a broad base, Romberg's sign was positive. Gait was with irregular steps and marked instability. Upper limb examination was normal. Both feet were pulseless.

Nerve conduction study revealed normal motor and sensory parameters in the median and ulnar nerves. In the lower limbs, the compound muscle action potentials (CMAPs) amplitude was severely reduced following stimulation of the peroneal and tibial nerves. The sural and peroneal sensory nerve action potentials were absent. Lumbar puncture showed elevated protein level
(504 mg/l, normal less than $460 \mathrm{mg} / \mathrm{l}$ ) and a normal cell count. Blood tests comprising full blood count, liver and kidney tests, sedimentation rate, several antibodies (rheumatoid factor, antinuclear antibodies, ANCA, anti-Hu, anti-Yo and anti-Ri), protein electrophoresis and vitamins were unremarkable. Anti-GM1 IgG antibodies titre was found to be as high as $12,582 \mathrm{U}$ (normal less than $800 \mathrm{U}$ ). Abdominal CT revealed bilateral partially thrombosed giant internal iliac artery aneurysms (see Fig.).

Surgical aneurysmorrhaphy was performed; the left aneurysm was removed, and the right one was excluded from systemic blood flow.
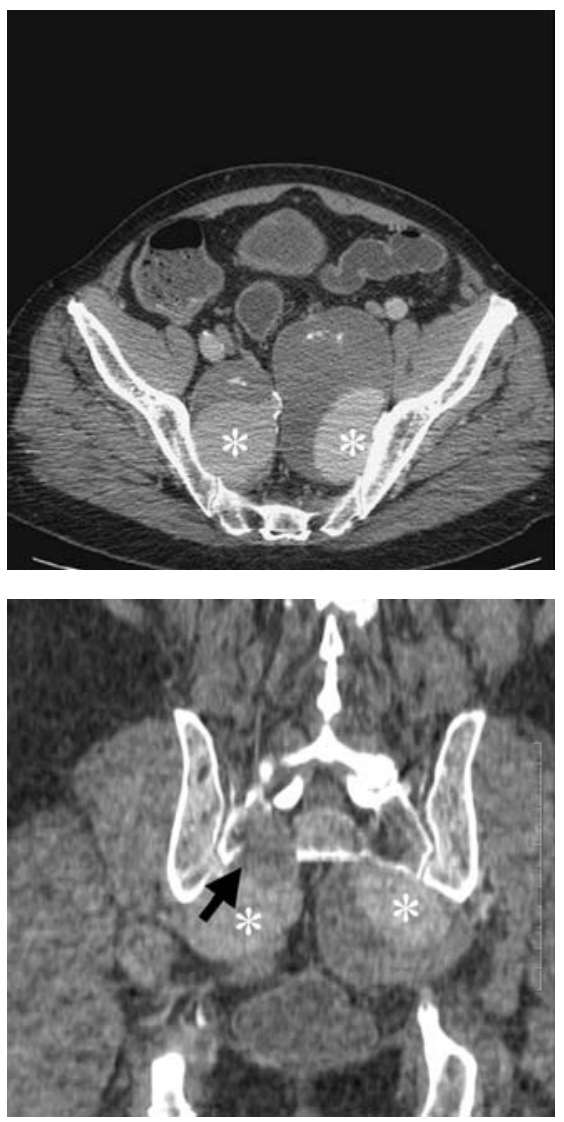

Fig. Multi-slice CT scan after IV iodinated contrast material injection. Axial transverse image (top) showing bilateral partially thrombosed giant internal iliac artery aneurysms $(*)$, the left one with a $6.7 \mathrm{~cm}$ diameter and a $4.2 \mathrm{~cm}$ thrombus, and the right one (actually located at the beginning of the obturator artery) with sacral bone erosion (arrows). Coronal (left) and sagittal (right) reconstructions showing sacral bone erosion by aneurismal masses (arrows) (bottom)
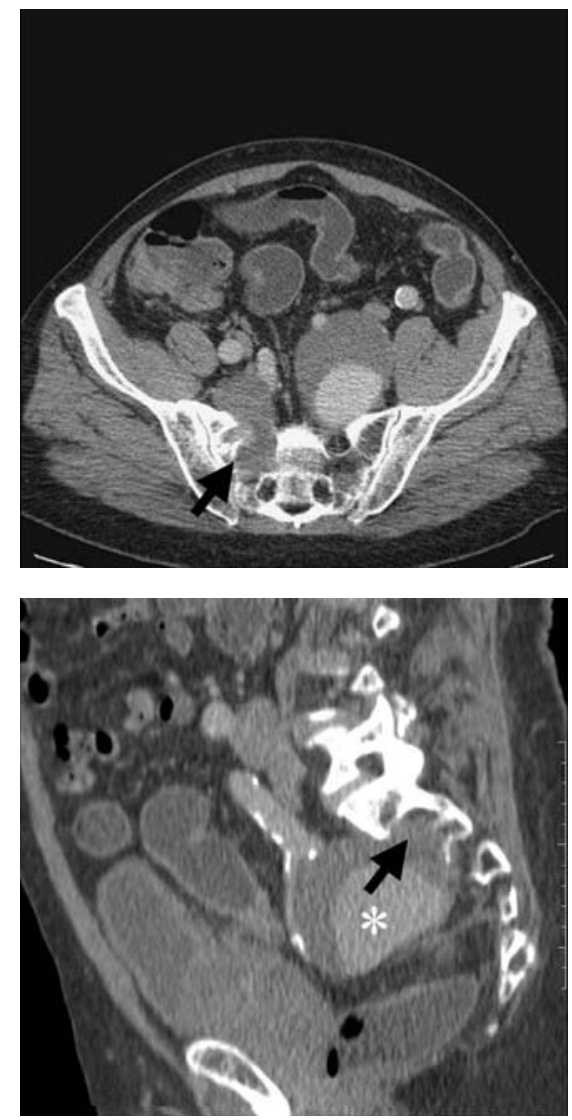

Three months later, the patient could again walk as he did before the operation, had no more pain, and anti-GM1 antibody titre had fallen to $6,001 \mathrm{U}$. Six months after the operation, the patient could walk for 20 minutes without help, and neurological examination showed improvement in the sensorimotor deficit and in balance and gait stability.

Two years after surgery, his condition had remained stable, and anti-GM1 antibodies were no longer detectable.

Our patient presented with bilateral lumbosacral plexopathy associated with partially thrombosed giant aneurysms of both

\section{을}


internal iliac arteries. This association suggests an unusual mechanism of plexus nerves damage by direct compression, which is strongly supported by the tight contact between aneurysms and nerves, along with the eroded aspect of the sacral bone (see Fig.).

Unilateral lumbosacral plexus compression has been exceptionally described in aneurysms of the common iliac artery [6] and of the internal iliac artery [4], in a pseudo-aneurysm following renal transplantation [8], and in a few more cases involving the internal iliac $[2,5]$ or gluteal arteries [10].

Although nerves are rather resistant to ischaemia and blood supply to the lumbosacral plexus is richly anastomosed, ischaemia might have played an additional role, through the combination of occluded internal iliac artery branches and direct mass effect, the latter including secondary vasa nervorum compression. Anatomically, along with the deep iliac circumflex and the lumbar segmental arteries, the internal iliac artery plays a major role in the blood supply of the lumbar and sacral plexuses, mainly through the iliolumbar, lateral sacral, and superior and inferior gluteal arteries [3]. Chronic ischaemic plexopathy can occur with aortic occlusion, and in stenosis and occlusion of iliac arteries. Acute lumbosacral plexopathies may be encountered as a rare complication of aortoiliac surgery, and in aortic dissection.

Alternate diagnoses in our case comprise polyradiculopathy, other causes of plexopathy and asymmetric axonal polyneuropathy that would have incidentally revealed the aneurysms. However, investigations clearly pointed to lumbosacral plexopathy, for which usual causes were reasonably excluded.

High anti-GM1 IgG antibodies titres are reported in lower motor neuron diseases, in axonal Guillain-Barré syndrome, and in sensorimotor neuropathy of undetermined origin $[1,7,9]$. In our case they were thought to reflect peripheral nerve damage, because clinical improvement was correlated to the fall in their serum titres after surgery.

Our patient presented with an unusual cause of bilateral lumbosacral plexopathy that was treated by decompression, and would have been potentially lethal if missed.

\section{References}

1. Adams D, Kuntzer T, Burger D, Chofflon M, Magistris MR, Regli F, Steck AJ (1991) Predictive value of anti-GM1 ganglioside antibodies in neuromuscular diseases: a study of 180 sera. J Neuroimmunol 32:223-230

2. al Asadi AD, le Fur R, al Amri A (1995) Motor deficit complicating an isolated aneurysm of the internal iliac artery. J Chir (Paris) 132:361-363

3. Day MH (1964) The blood supply of the lumbar and sacral plexuses in the human foetus. J Anat 98:104-116

4. Delgado-Garcia F, Lopez-Dominguez JM, Casado-Chocan JL, Blanco-Ollero A, Robledo-Strauss A, Mendez-Sangil B, Diaz-Espejo C (1999) Lumbosacral plexopathy as a form of presentation of an aneurysm of the iliac artery. Rev Neurol (Paris) 28:1072-1074
5. Eekhof JL, Ansink BJ, Davies GE (1990) Iliac aneurysms. J Neurol Neurosurg Psychiatry 53:927

6. Giraldi C, Merlini V, Mosca F, Ferrari M (1984) Compression of the lumbosacral plexus in a case of voluminous aneurysm of the common iliac artery. Riv Neurol (Paris) 54:399-404

7. Kornberg AJ (2000) Anti-GM1 ganglioside antibodies: their role in the diagnosis and pathogenesis of immunemediated motor neuropathies. J Clin Neurosci 7:191-194

8. Luzzio CC, Waclawik AJ, Gallagher CL, Knechtle SJ (1999) Iliac artery pseudoaneurysm following renal transplantation presenting as lumbosacral plexopathy. Transplantation 67:1077-1078

9. McCombe PA, Wilson R, Prentice RL (2000) Results of testing for anti-GM1 antibodies. J Clin Neurosci 7:209-212

10. Yurtseven T, Zileli M, Goker EN, Tavmergen E, Hoscoskun C, Parildar M (2002) Gluteal artery pseudoaneurysm, a rare cause of sciatic pain: case report and literature review. J Spinal Disord Tech 15:330-333

Ch. Wider, MD (四) · Th. Kuntzer, MD • J. Bogousslavsky, MD · F. Vingerhoets, MD Service de Neurologie CHUV

1011 Lausanne, Switzerland

Tel.: + 41-21/3141111

Fax: + 41-21/3141244

E-Mail: christian.wider@chuv.ch

L.-K. Von Segesser, MD

Cardiovascular Surgery Department

Centre Hospitalier Universitaire Vaudois

Rue du Bugnon

1011 Lausanne, Switzerland

S. D. Qanadli, MD, PhD

Radiology Department

Centre Hospitalier Universitaire Vaudois

Rue du Bugnon

1011 Lausanne, Switzerland 